\title{
Homens homossexuais idosos e de meia-idade nas mídias digitais: autodescrição, apoio social e qualidade de vida
}

\section{| ${ }^{1}$ João Paulo Ferreira, ${ }^{2}$ Keika Inouye, ${ }^{3}$ Richard Miskolci |}

Resumo: O objetivo deste estudo é identificar e analisar os indicadores de qualidade de vida e apoio/suporte social, bem como os descritores do perfil utilizados por homens de meia-idade que buscam e/ou se interessam por relaçóes com o mesmo sexo em plataformas digitais. O desenho metodológico é de natureza quantitativa, descritiva de corte transversal. A coleta de dados foi realizada por meio de um questionário sociodemográfico, o WHOQOLbref e a Escala de Apoio Social do Medical Outcomes Study (MOS). Os dados foram analisados com auxílio do Statistical Package for the Social Sciences ${ }^{\circledR}$ (SPSS). Os resultados confirmaram que os descritores mais prevalentes foram aqueles que buscaram se desvencilhar de noçôes que pudessem remeter ao universo da maturidade e velhice fragilizadas, além do reforço às representaçôes hegemônicas de masculinidade. Em relação aos escores totais de apoio social e qualidade de vida, estes apresentaram correlação diretamente proporcional, significativa e de magnitude moderada ( ho $=0,609, \mathrm{p}<0,001)$.

> Palavras-chave: homossexualidade; envelhecimento; qualidade de vida; apoio social; mídias digitais.

\author{
${ }^{1}$ Department of the History \\ of Science, Harvard University. \\ Cambridge-MA, United States. \\ Departamento de Sociologia, \\ Universidade Federal de São \\ Carlos. São Carlos-SP, Brasil. \\ (joaopauloferreira@g.harvard.edu). \\ ORCID: 0000-0003-0115-9032 \\ ${ }^{2}$ Departamento de Gerontologia, \\ Universidade Federal de São \\ Carlos. São Carlos-SP, Brasil \\ (keikain@ufscar.br). \\ ORCID: 0000-0001-5735-7623 \\ ${ }^{3}$ Escola Paulista de Medicina, \\ Universidade Federal de São \\ Paulo. São Paulo-SP, Brasil \\ (richard.miskolci@unifesp.br). \\ ORCID: 0000-0002-6405-5591
}

Recebido em: 07/06/2019 Aprovado em: 06/11/2019 Revisado em: 02/06/2020 


\section{Introdução}

As novas redes, mediadas digitalmente em escala global, impactaram localmente na maneira pela qual as pessoas organizam suas vidas, as relaçôes de trabalho, criam vínculos de amizade e solidariedade, buscam informaçóes e se engajam em grupos de apoio e suporte social (BAYM, 2010). Esse processo tem crescimento exponencial a partir da disponibilização comercial de internet, que no Brasil data de meados dos anos 1990 (MISKOLCI, 2013; 2017).

Grupos historicamente estigmatizados, e sem reconhecimento público de questóes relativas às esferas afetiva, sexual e de direito, encontraram nos novos espaços mediados on-line ambientes capazes de proporcionar socialização e o estabelecimento de redes de apoio e suporte social, ainda que provisórias. Estes grupos, com destaque para sujeitos homossexuais mais velhos da perspectiva etária e que residem na cidade de São Paulo, compóem uma geração de pessoas que viveram suas experiências sociais e amorosas principalmente off-line, em espaços pouco acolhedores, reconhecidos pelo histórico de violência, intimidação e perseguição (MISKOLCI, 2013; 2017; GUIMARÁES, 2004; PERLONGHER, 1987; FERREIRA, 2017; ZAGO, 2013; HENNING, 2016). Assim, o presente artigo parte de uma pesquisa empírica que investigou a sociabilidade de sujeitos homossexuais de meia-idade e acima (40 anos ou mais), os quais buscavam relaçóes amorosas, sexuais ou de amizade em duas plataformas digitais de relacionamento - no Disponivel.com e nas salas de batepapo do portal Universo Online.

O objetivo da pesquisa consistiu em descrever e analisar a relaçáo entre qualidade de vida e suporte social, atrelados à caracterização sociodemográfica dos interlocutores, por meio do Instrumento de Avaliação de Qualidade de Vida (WHOQOL-bref) e da Escala de Apoio Social do Medical Outcomes Study (MOS), ambos validados nacionalmente e com ampla utilização internacional. Além disso, a pesquisa também buscou investigar a forma como os sujeitos se descreviam nas duas plataformas e o que eles buscavam, de modo que a autodescrição e as buscas, como apontado por Ferreira e Miskolci (2020), não operam como algo meramente descritivo e individual, mas produzem e reiteram representaçôes coletivas sobre o desejo e sobre a sexualidade, promovendo agenciamentos e/ou normatizaçôes de gênero.

A amostra escolhida, que compreende interlocutores nascidos até 1978, compóe uma amostra cuja sociabilidade se deu predominantemente de maneira face a face, 
com práticas e em circuitos relacionais anteriores à disponibilização comercial de internet. Esses sujeitos possuem um histórico de experiências sociais comuns marcadas pela busca por socialização em lugares conhecidos como "guetos" - isto é: parques, cinemas, saunas, estacionamentos, ruas comerciais em períodos noturnos, bares e banheiros públicos - conforme apontou o antropólogo Néstor Perlongher (1987), em pesquisa pioneira na cidade de São Paulo na década 1980. Não obstante, mesmo após a invenção e disseminação das redes on-line, das salas de bate-papo e dos aplicativos com finalidades amorosas e/ou sexuais, há ainda permanências com as buscas face a face do passado, segundo pesquisas socioantropológicas recentes, a partir de Henning (2016), Motta (2014), Pocahy (2012), Saggese (2015) e Santos e Pereira (2016). Estes lugares, organizados em territórios, ficaram conhecidos pela busca casual por sexo anônimo principalmente durante os anos 1980 nas regióes centrais da cidade de São Paulo, sendo identificados por territórios de "pegação" (PERLONGHER, 1987).

Para desenvolver o estudo, partimos da compreensão de que o elemento psicológico e emocional da vida contemporânea está intimamente vinculado ao desenvolvimento das novas tecnologias e dos espaços digitais de interação. Isto, pois, com a internet há a possibilidade de criar laços fortes e redes voltadas à amizade e ao apoio/ajuda mútua (BAYM, 2010; MISKOLCI, 2017; FACIOLI; MISKOLCI, 2015; BELELI, 2012; CASTELLS, 2011; DIJCK, 2013), assim como a criação de laços fracos, de modo anônimo e guardando, em grande medida, o senso de segurança, autonomia e proteção, o que não era possível antes da experiência com a internet, uma vez que os espaços interativos eram quase sempre marcados pela exposição (BAYM, 2010; MISKOLCI, 2017).

Uma interpretação unidimensional na perspectiva econômica não reconheceria aspectos positivos envolvendo o uso dessas mídias, os quais auxiliam a lidar com formas de desigualdade como as de gênero e sexualidade. Para sujeitos como mulheres e homossexuais, criar contatos on-line foi um contraste com as possibilidades limitadas existentes na vida pré-internet, quando as pessoas eram obrigadas a priorizar relações comunitárias, frequentemente controladoras e heterossexistas. Nesse sentido, o que alguns poderiam criticar como o caráter individualizador do uso dessas tecnologias logrou criar certo grau de autonomia para aqueles e aquelas cujo controle comunitário criado pelos laços fortes com família, colegas de trabalho ou estudo impunham limites morais estritos aos seus desejos sexuais e aspiraçóes amorosas (MISKOLCI, 2017, p. 101).

Martino (2015), Wellman (2001) e Miskolci (2017) reconhecem que os chamados "laços fracos", aqueles frequentemente estabelecidos em espaços digitais 
de interação, podem ser benéficos, pois garantem as facilidades de rompimento, sem necessariamente haver dano ou consequências negativas nas relaçóes diárias, como também podem ser mais atrativos do ponto de vista das redes que se organizam por interesses eróticos e/ou amorosos comuns. Assim, tais laços:

permitem estabelecer contato com pessoas fora do círculo mais próximo de amigos e parentes - os laços fortes - e, portanto, criar ligaçóes com indivíduos socialmente distantes (MARTINO, 2015, p. 69).

Se a organização psicológica da vida, analisada por Nicolaci-da-Costa (2002) e Eva Illouz (2012), foi profundamente transformada pelas novas tecnologias e suas redes correspondentes, quais seriam os indicadores de qualidade de vida de sujeitos homossexuais de meia-idade, que fazem parte de uma geração pré-internet, em que as dinâmicas de socialização constituíram-se predominantemente face a face em territórios pouco acolhedores e reconhecidos pelo histórico de violência, estigma e preconceito? Haveria relação entre o apoio/suporte social e a qualidade de vida destes sujeitos? O que os dados sociodemográficos, a descrição do perfil e as buscas on-line revelam em termos sociológicos?

A qualidade de vida, interpretada como um conceito multidimensional definido pela Organização Mundial da Saúde (OMS), abarca percepções individuais e coletivas relacionadas ao meio ambiente e à compreensão de si, além de reconhecer os aspectos culturais e os conjuntos de valores que determinam os objetivos, as expectativas, preocupaçóes e os padrôes sociais (1995). De acordo com Inouye (2010) et al., o construto da qualidade de vida integra os domínios do bem-estar, prazer, a capacidade de desejar e a satisfação com a vida. Estes domínios representam dimensóes centrais na maneira pela qual as pessoas avaliam as relaçooes sociais, interagem e sentem satisfação.

Além disso, interpretamos que a qualidade de vida e as dinâmicas de apoio/suporte social também podem sofrer mudanças positivas em razão das novas possibilidades interativas e relacionais via internet, uma vez que os espaços digitais auxiliam no combate ao isolamento e na ampliação dos laços interpessoais, formando redes de apoio e esperança a segmentos e grupos marginalizados publicamente (FACIOLI; MISKOLCI, 2015; BELELI, 2012; CASTELLS, 2011; DJICK, 2013; MARTINO, 2015; WELLMAN, 2001; NICOLACI-DA-COSTA, 2002; ILLOUZ, 2012).

Uma rede social que fornece um apoio inapropriado pode estar relacionada com diversos aspectos táo amplos, que extrapolam condiçóes patológicas e poderia estar associada 


\begin{abstract}
diretamente a indicadores de mortalidade, levando não somente a uma população idosa sob maior risco e vulnerabilidade, mas também apresentando risco iminente de questôes extremamente preocupantes na população jovem e adulta, como é o exemplo dos casos de tendência a suicídios em populaçóes que geralmente estão sob efeito de alguma condiçấo de risco à saúde e que possuem níveis de apoio social inadequados (GUEDES et al., 2017, p. 1.188).
\end{abstract}

Desta forma, a pesquisa justifica-se pela possibilidade de analisar questóes subjetivas e sociais, lidando com interlocutores de meia-idade e acima, que vivenciam on-line experiências amorosas, sexuais e de amizade.

\title{
Metodologia
}

O estudo caracterizou-se como quantitativo e descritivo. Desta forma, o delineamento limitou-se a descrever o fenômeno observado, sem manipulação de variáveis e, portanto, sem inferir relaçóes de causalidade.

Os dados foram coletados por aluno de graduação em Gerontologia habilitado na utilização dos instrumentos e participante de grupos de pesquisa na área de Gerontologia e Sociologia. O período de coleta ocorreu nos anos de 2013 e 2014. A amostra foi composta por homens com idades entre 40 e 65 anos $(\mathrm{N}=103)$ que buscam e/ou se interessam por relaçóes com o mesmo sexo.

O convite para participação na pesquisa foi realizado por meio de duas plataformas on-line: as salas de bate-papo do portal Universo Online (UOL) e o Disponivel. com. Estas plataformas foram escolhidas por conveniência por se tratarem de locais de elevado acesso de pessoas com o critério de inclusão da amostra: se relacionar com pessoas do mesmo sexo. Não foi realizado cálculo amostral, sendo esta uma amostra de conveniência. Porém, há que se valorizar a composição desta, tendo em vista a dificuldade para se conseguir interlocutores, sendo o percentual de recusa alto e igual a 85,3\% ( $\mathrm{N}^{\text {total }} 700$ interações on-line).

A partir de contato inicial com os possíveis interlocutores da pesquisa por meio das plataformas citadas, aqueles que aceitavam eram redirecionados a uma segunda plataforma - Survey Monkey -, a qual continha em formato digital o Instrumento de Avaliação de Qualidade de Vida (WHOQOL-bref), a Escala de Apoio Social do Medical Outcomes Study (MOS) e o questionário de caracterização sociodemográfica. 
O WHOQOL-bref possui 26 questôes; duas sobre a qualidade de vida em geral e as demais representam as 24 facetas que compóem o instrumento não abreviado - WHOQOL-100. O WHOQOL-bref abarca quatro domínios: físico, psicológico, relaçôes sociais e meio ambiente. $\mathrm{O}$ domínio físico abarca questôes sobre capacidade para o trabalho; dor e desconforto; energia e fadiga; sono e repouso; mobilidade; atividades da vida cotidiana; dependência de medicação e tratamentos. O domínio psicológico refere-se a sentimentos positivos; pensar, aprender, memória e concentração; autoestima, imagem corporal e aparência; sentimentos negativos; espiritualidade, religião e crenças pessoais. O domínio relaçôes sociais envolve relaçóes pessoais, apoio e atividade sexual. O domínio meio ambiente engloba segurança física e proteção, ambiente no lar, recursos financeiros, disponibilidade e qualidade de cuidados à saúde e sociais; oportunidades de adquirir novas informações e habilidades; recreação e lazer; transporte; ambiente físico (poluição, ruído, trânsito e clima). Os valores foram padronizados numa escala de 100 pontos segundo recomendação do grupo brasileiro de Qualidade de Vida da Organização Mundial da Saúde (World Health Organization Quality of Life Group). Os escores mais elevados significam melhor qualidade de vida (WHOQOL, 1995).

A Escala de Apoio Social do Medical Outcomes Study (MOS) possui 19 itens que contemplam cinco dimensóes: (a) material: que se refere à disponibilidade de pessoas para ajudar quando o indivíduo está doente; (b) afetiva: que coloca questôes de amor, bem-querer, afetividade e toque (abraço); (c) emocional: que envolve confiança, escuta, compartilhamento de problemas e compreensão; (d) interação social positiva: que engloba diversão, relaxamento, distração e momentos agradáveis com outras pessoas e (e) informação: que abarca a disponibilidade de pessoas para dar bons conselhos, sugestôes e informaçóes ${ }^{25}$. Para cada item, o participante indicou em escala Likert qual a frequência de disponibilidade ("nunca" a "sempre"). Os valores foram padronizados numa escala que poderia variar entre 20 e 100 pontos, segundo as orientaçóes dos pesquisadores que construíram a escala. Os escores mais elevados significam melhores condiçóes de apoio social (GRIEP et al., 2005).

O Critério de Classificação Econômica Brasii ${ }^{26}$ foi utilizado para descrever o nível socioeconômico, por meio do poder aquisitivo familiar, baseando-se na quantidade de bens de consumo duráveis, do grau de instrução do chefe da família e outros fatores como a presença de empregada mensalista. Este critério divide a população em oito níveis (A1, A2, B1, B2, C1, C2, D e E) (ABEP, 2012). 
A plataforma Survey Monkey gerou um banco de dados em planilha, não sendo necessária digitação de dados. Estes foram incluídos no programa IBM-Statistical Package for Social Sciences (SPSS), for Windows, versão 21.0, para realização de:

(1) análises descritivas para caracterizar o perfil dos participantes, a qualidade de vida e o apoio social - para as variáveis contínuas foram realizadas medidas de posição e dispersão (média, mediana, desvio padrão, mínimo e máximo) e para as variáveis categóricas foram feitas medidas de frequência com valores absolutos (n) e relativos (\%).

(2) análise de correlação de Spearman a fim de identificar a relação entre os escores de qualidade de vida e apoio social. A escolha deste teste náo paramétrico se deu pelo fato de os dados não apresentarem distribuição normal verificada pelo teste de teste de Kolmogorov - Smirnov $(\mathrm{p}<0,05)$. Por fim, para melhor visualização dos dados, foi feito scatter plot (gráfico de dispersão) para a visualização bidimensional dos dados de apoio social e qualidade de vida. Foi considerado como nível de significância estatística o valor de 5\% ( $<<0,05)$.

Salientamos, ainda, que o conceito "rede social" possui - ao menos - duas definiçóes possíveis para o presente artigo; a primeira delas se assemelha à noção de comunidade(s) criada(s) em ambiente on-line, e que define em grande medida a relação estabelecida entre sujeitos distintos e seus laços fortes ou fracos correspondentes; a segunda, por outro lado, pode ser caracterizada pelas redes estabelecidas em ambientes off-line (face a face), cuja representação geralmente está circunscrita às relaçóes interpessoais estabelecidas em ambientes domésticos (como a casa em que se vive e nas relaçôes cotidianas com a família biológica etc.), de trabalho e de lazer. Em relação à definição de "apoio" e "suporte" social, estas são utilizadas em consonância à denominação criada pela Organização da Mundial da Saúde e incorporada pela Política Nacional de Saúde da Pessoa Idosa, referida pelos princípios e diretrizes do Sistema Único de Saúde (BRASIL, 2006; GUEDES et al., 2017); assim, o apoio e o suporte social se estabelecem como um domínio da saúde e aglutinam o suporte emocional, financeiro, instrumental e aqueles oriundos de relacionamento social vinculados a pessoas e/ou instituiçôes, conforme Guedes et al. (2017), Melchiorre et al. (2013) e Neri e Vieira (2013).

A pesquisa foi aprovada pelo Comitê de Ética em Pesquisa com Seres Humanos (No 300.177/2013) da universidade sede. 


\section{Resultados}

Pela análise da autodescrição contida no perfil dos participantes das duas plataformas, observa-se a utilização, em ordem decrescente, dos descritores "discreto", "fora do meio", "sarado", “coroa”, "paizão" e "urso" (figura 1).

Figura 1. Descrição pessoal utilizada nas duas plataformas, com repetiçôes. 2013-2014. São Paulo, Brasil

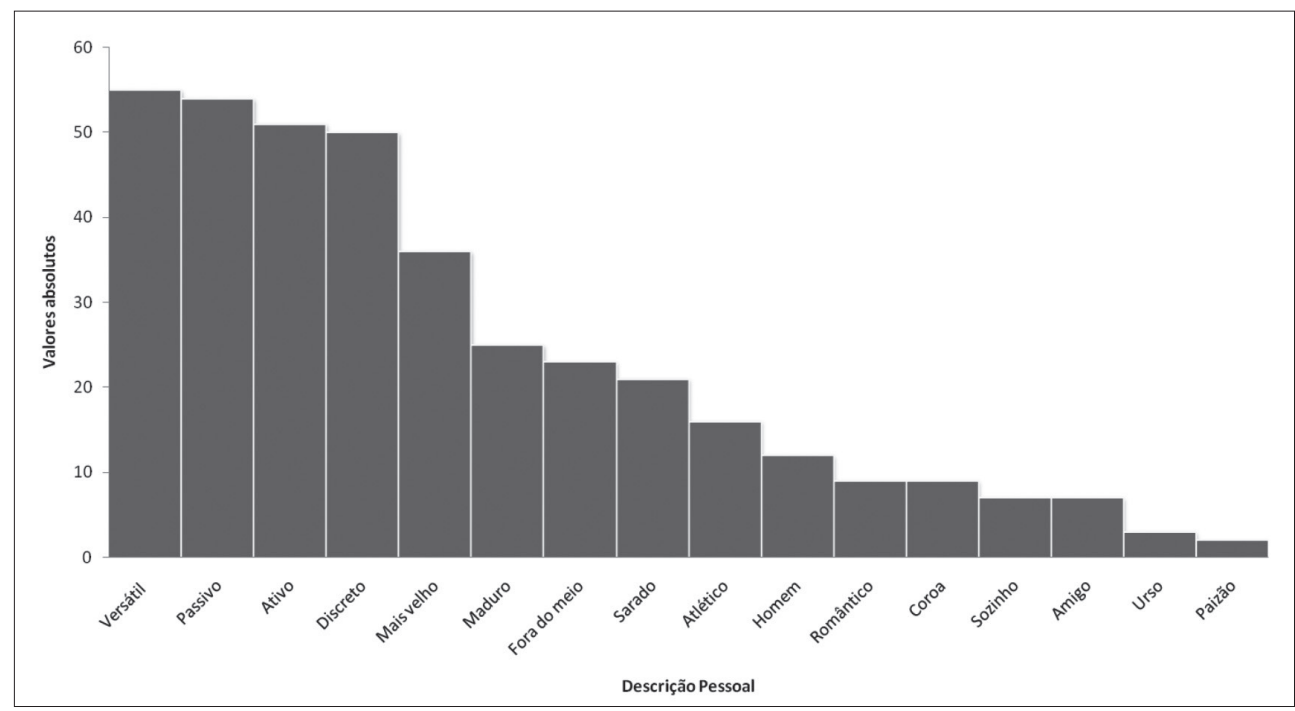

A a mostra foi composta por homens com idade média igual a 45,8 anos ( $\mathrm{DP}=5,67)$, com alta escolaridade - ensino superior completo em sua maioria, e pertencentes a classes sociais mais altas (A e B). As classes A e B, em valores atualizados no ano de 2016, tinham poder aquisitivo superior a $\mathrm{R} \$ 4,852,00$. A situação familiar mais comum foi de solteiros $(62,1 \%, \mathrm{n}=64)$ e sem filhos $(80,6 \%, \mathrm{n}=83)$.

Em relação à religião, a maioria dizia ter uma e houve grande variação - as mais citadas foram: católica $(25,2 \%, n=26)$, espírita $(26,2 \%, n=27)$ e protestante $(26,2 \%$, $\mathrm{n}=27$ ). Os dados descritivos detalhados da amostra são apresentados na tabela 1 . 
Tabela 1. Distribuição e análise descritiva das características sociodemográficas da amostra de homens com 40 anos ou mais que se relacionam com pessoas do mesmo sexo. 2013-2014. São Paulo, Brasil

\begin{tabular}{|c|c|c|c|c|c|c|c|}
\hline $\begin{array}{l}\text { CARACTERÍSTICAS } \\
\text { SOCIODEMOGRÁFICAS }\end{array}$ & $\begin{array}{l}\text { Frequência } \\
\text { Absoluta }\end{array}$ & $\begin{array}{l}\text { Frequência } \\
\text { Relativa }\end{array}$ & Média & Mediana & DP & Mín. & Máx. \\
\hline Idade (anos) & - & - & 45,82 & 45,00 & 5,655 & 40 & 62 \\
\hline \multicolumn{8}{|l|}{ Escolaridade } \\
\hline Ensino fundamental completo & 1 & 1,0 & & & & & \\
\hline Ensino médio incompleto & 3 & 2,9 & & & & & \\
\hline Ensino médio completo & 14 & 13,6 & & & & & \\
\hline Superior incompleto & 29 & 28,2 & & & & & \\
\hline Superior completo & 27 & 26,2 & & & & & \\
\hline Pós-graduação & 29 & 28,6 & & & & & \\
\hline Total & 103 & 100,0 & & & & & \\
\hline \multicolumn{8}{|l|}{ Classe social } \\
\hline A1 & 0 & 0 & & & & & \\
\hline A2 & 10 & 9,7 & & & & & \\
\hline B1 & 30 & 29,1 & & & & & \\
\hline B2 & 29 & 28,2 & & & & & \\
\hline $\mathrm{C} 1$ & 20 & 19,4 & & & & & \\
\hline $\mathrm{C} 2$ & 10 & 9,7 & & & & & \\
\hline $\mathrm{D}$ & 4 & 3,9 & & & & & \\
\hline E & 0 & 0 & & & & & \\
\hline
\end{tabular}

\section{Situação conjugal}

$\begin{array}{lcc}\text { Casado } & 28 & 27,2 \\ \text { Solteiro } & 64 & 62,1 \\ \text { Separado/Divorciado } & 10 & 9,7 \\ \text { Viúvo } & 1,0 & 1,0\end{array}$

Filhos

Não tem

Tem
83

20

$$
0,34 \quad 0,00
$$$$
\begin{array}{lll}
0,774 & 0 & 3
\end{array}
$$

80,6

19,4

continua... 


\begin{tabular}{|c|c|c|c|c|c|c|c|}
\hline $\begin{array}{l}\text { CARACTERÍSTICAS } \\
\text { SOCIODEMOGRÁFICAS }\end{array}$ & $\begin{array}{l}\text { Frequência } \\
\text { Absoluta }\end{array}$ & $\begin{array}{l}\text { Frequência } \\
\text { Relativa }\end{array}$ & Média & Mediana & DP & Mín. & Máx. \\
\hline \multicolumn{8}{|l|}{ Problemas de saúde (autorrelato) } \\
\hline Não tem & 78 & 75,7 & & & & & \\
\hline Tem & 25 & 24,3 & & & & & \\
\hline \multicolumn{8}{|l|}{ Religião } \\
\hline Católico & 26 & 25,2 & & & & & \\
\hline Espírita & 27 & 26,2 & & & & & \\
\hline Protestante & 27 & 26,2 & & & & & \\
\hline Evangélico & 9 & 8,7 & & & & & \\
\hline Agnóstico & 6 & 5,8 & & & & & \\
\hline Ateu & 5 & 4,9 & & & & & \\
\hline Budista & 1 & 1,0 & & & & & \\
\hline Umbandista & 1 & 1,0 & & & & & \\
\hline Candomblé & 1 & 1,0 & & & & & \\
\hline \multicolumn{8}{|l|}{ Homossexualidade } \\
\hline Assumida na sociedade & 52 & 50,5 & & & & & \\
\hline Não assumida na sociedade & 51 & 49,5 & & & & & \\
\hline
\end{tabular}

Os dados descritivos que precederam às análises correlacionais evidenciaram bons escores gerais de qualidade de vida, porém nota-se que os escores mais baixos se referem aos domínios de relaçôes sociais e meio ambiente. No que tange ao apoio social, os dados apontam que homens que se relacionam com pessoas do mesmo sexo têm escores mais baixos nos domínios emocional e informação (tabela 2). 
Tabela 2. Análise descritiva de qualidade de vida e apoio social da amostra de homens com 40 anos ou mais que se relacionam com pessoas do mesmo sexo. 2013-2014. São Paulo, Brasil

\begin{tabular}{|c|c|c|c|c|c|}
\hline \multirow[t]{2}{*}{ VARIÁVEIS } & \multicolumn{5}{|c|}{ ANÁLISES ESTATÍSTICAS DESCRITIVAS } \\
\hline & Média & Mediana & DP & Mínimo & Máximo \\
\hline \multicolumn{6}{|l|}{ QUALIDADE DE VIDA } \\
\hline $\begin{array}{l}\text { Questâo geral de qualidade de vida } \\
\text { (1ª. Questão) }\end{array}$ & 4,01 & 4,00 & 0,87 & 1 & 5 \\
\hline Questão Geral de Saúde (2a. Questão) & 3,70 & 4,00 & 1,12 & 1 & 5 \\
\hline Físico & 73,30 & 75,00 & 15,31 & 25 & 100 \\
\hline Psicológico & 71,60 & 75,00 & 15,36 & 17 & 96 \\
\hline Relaçóes sociais & 66,30 & 67,00 & 21,71 & 8 & 100 \\
\hline Meio ambiente & 64,26 & 66,00 & 15,88 & 25 & 100 \\
\hline Total & 68,82 & 71,40 & 14,08 & 23,7 & 94,50 \\
\hline \multicolumn{6}{|l|}{ APOIO SOCIAL } \\
\hline Material & 79,13 & 80,00 & 18,84 & 25 & 100 \\
\hline Afetivo & 83,27 & 93,00 & 20,25 & 27 & 100 \\
\hline Emocional & 74,95 & 80,00 & 23,44 & 20 & 100 \\
\hline Interação social positiva & 79,85 & 85,00 & 21,08 & 25 & 100 \\
\hline Informação & 75,58 & 80,00 & 21,31 & 30 & 100 \\
\hline Total & 74,40 & 78,00 & 18,24 & 28 & 95 \\
\hline
\end{tabular}

Os domínios de apoio social e qualidade de vida evidenciaram algumas correlaçôes significantes e importantes, dentre as quais se destacam correlaçóes positivas e de magnitude moderada entre: (a) a disponibilidade de informação e os domínios psicológico (rho=0,540; $\mathrm{p}=0,000$ ), relaçóes sociais ( $\mathrm{rho}=0,603 ; \mathrm{p}=0,000$ ) e meio ambiente (rho=0,512; $\mathrm{p}=0,000)$ da qualidade de vida; (b) a disponibilidade de interação social positiva e os domínios psicológico ( $(\mathrm{hho}=0,630 ; \mathrm{p}=0,000)$ e relaçóes sociais (rho=0,693; $\mathrm{p}=0,000)$ da qualidade de vida; (c) a disponibilidade de apoio afetivo emocional e o domínio relaçôes sociais (rho=0,614; $\mathrm{p}=0,000)$ da qualidade de vida. Até mesmo os domínios físicos e o meio ambiente da qualidade de vida tinham relação positiva e de intensidade fraca e moderada, respectivamente, com a disponibilidade de apoio social (rho=0,256; $\mathrm{p}=0,009$ e rho=0,489; $\mathrm{p}=0,000$ ) (Tabela 3).

Os escores totais de apoio social e qualidade de vida apresentaram correlação significante, positiva e de magnitude moderada (tabela 3, figura 2). 


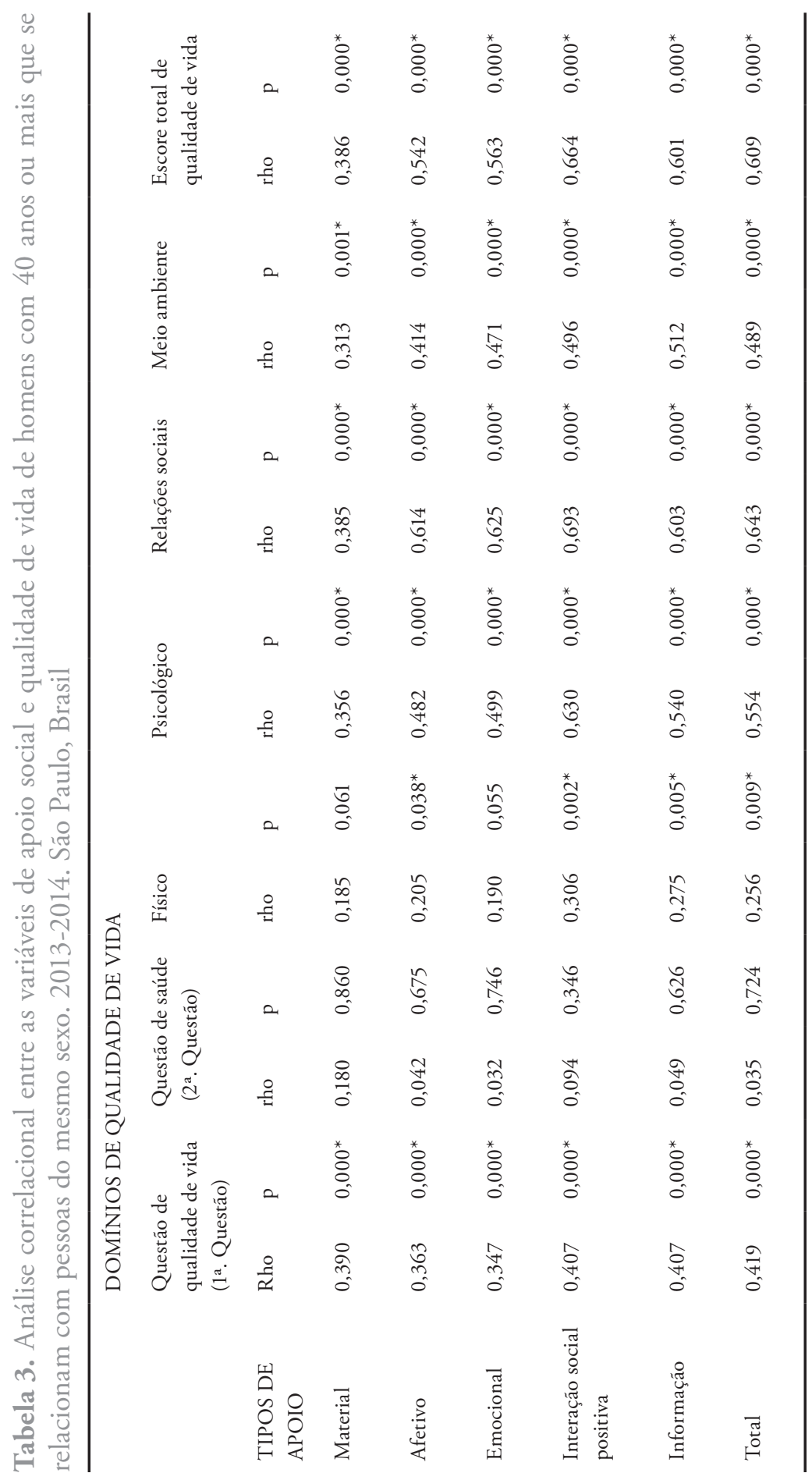




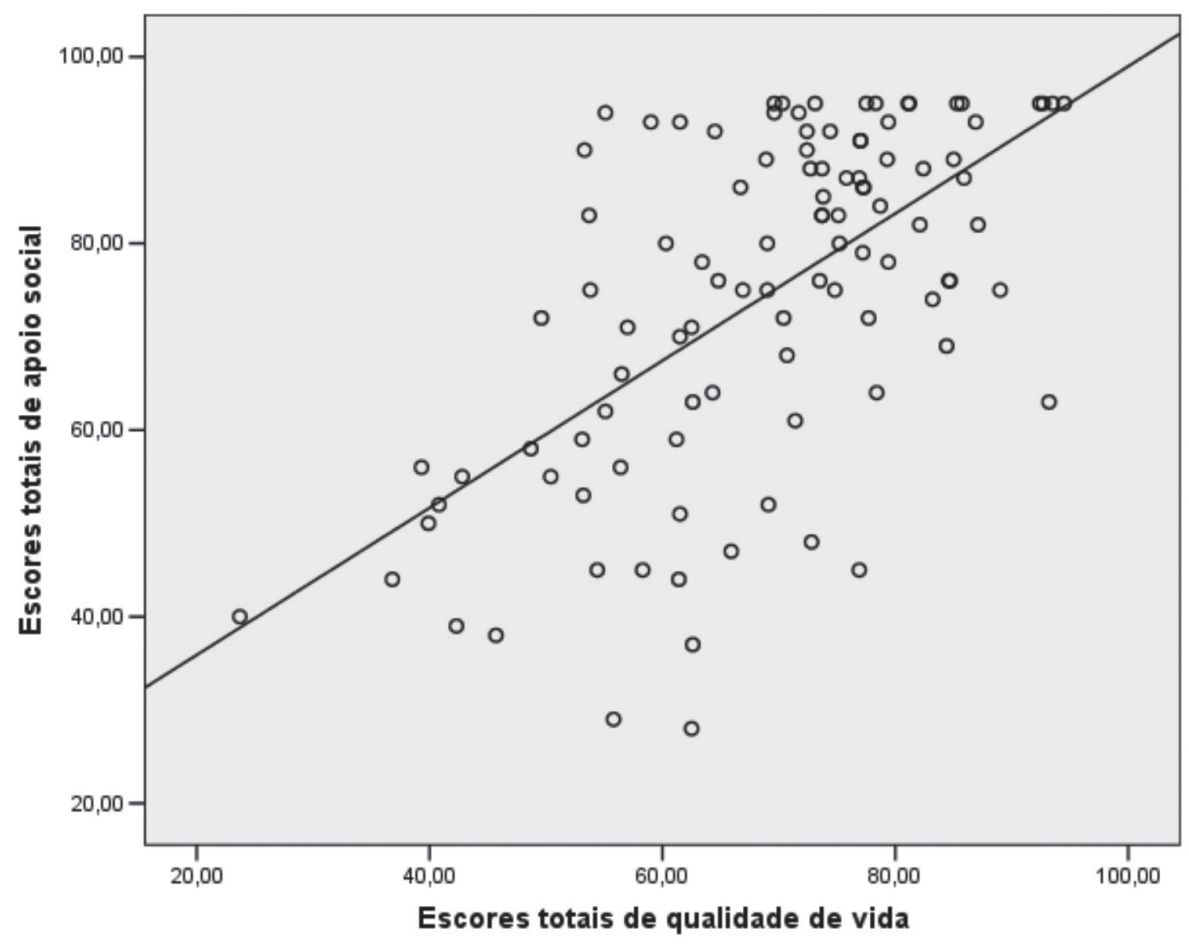

\section{Discussão}

\section{Idade, renda e escolaridade}

Iniciando pelos dados sociodemográficos obtidos - idade, renda e escolaridade - os quais podem ser pensados como categorias analíticas e interseccionais (BRAH, 2006) -, notamos que a faixa etária relatada compreende, maiormente, sujeitos de meia-idade (40 a 50 anos). Os dados para escolarização e renda, de forma geral, representam uma amostra com elevado capital econômico e educacional. A despeito disso, ponderamos que as características sociodemográficas encontradas podem ter tido um saldo positivo, pois o método de amostra por conveniência pode ser impreciso e não isento de vieses, sobretudo porque pessoas com elevado capital educacional e econômico podem estar mais interessadas em participar de pesquisas acadêmicas. 
De qualquer forma, convém refletir que, geracionalmente, pessoas entre 40 e 50 anos de idade no Brasil fazem parte de uma geração que nasceu em fins dos anos 1960, estendendo-se até 1978. Em 1960, a taxa de analfabetismo prevista para a população com 15 anos e mais era de, aproximadamente, 39,7\% - o que marca, ainda, uma ruptura com a Série Histórica do IBGE, pois até 1950 este indicador representava mais da metade da população brasileira como analfabeta (50,6\%) (IBGE, 2016).

Assim, depreende-se que os indicadores de escolaridade, maiormente agrupados nas categorias "superior incompleto", "superior completo" e "pós-graduação", revelam uma disparidade em termos geracionais, em que há prevalência de usuários com elevado índice de escolarização, o que não é representativo da própria coorte sob o prisma da geração, partindo da Série Histórica (IBGE, 2016) relativa ao analfabetismo na população brasileira. A amostra analisada, consequentemente, corrobora uma parcela de sujeitos com melhores indicadores relativos à renda e escolaridade, o que também marca, entretanto, uma característica da natureza amostral.

Recentes pesquisas que lidam com os usos de internet demonstraram que houve incremento quantitativamente significativo de usuários desde 2010, o que pode ser explicado, em grande medida, pelas políticas dos dois governos democráticos anteriores, com a ampliação do acesso ao crédito pelas classes populares desde 2005, redução das taxas incidentes sobre computador, celular e rede de telefonia móvel, o que permitiu uma espécie de "explosão demográfica" de usuários conectados a partir de 2012 (CASTELLS, 2011; DIJCK, 2013; MARTINO, 2015; MISKOLCI, 2017).

De acordo com a Pesquisa Nacional por Amostras de Domicílio (IBGE, 2016), entre 2008 e 2014 a posse de celulares de tipo smartphone - modelo de origem inglesa, voltado às tecnologias avançadas, similares àquelas operacionalizadas pelos computadores - cresceu 56\%, havendo, em 2015, uma extrapolação dos usos de internet por smartphone em comparação aos usos por computador doméstico e pessoal. Pode-se inferir, deste modo, que o processo de "democratizaçáo" dos usos de internet é, ainda, um fenômeno recente e não acabado, em que persistem desigualdades tocantes à faixa etária, por exemplo, tal qual se vê pelos dados obtidos neste estudo, por meio da prevalência de pessoas entre 40 e 50 anos com elevado índice de escolarização e renda (MISKOLCI, 2017; IBGE, 2016).

Este dado, à luz da literatura acadêmica, nos permite questionar se as relaçóes criadas on-line e mediadas digitalmente formam, de fato, redes que se desenvolvem democraticamente e de modo irrestrito, convergindo sujeitos de origens sociais 
diversas, sobretudo em relação aos sujeitos mais velhos em termos etários. O que nos parece apropriado concluir sobre este ponto, preliminarmente, é que as redes digitais no Brasil, ainda que mais abertas e geograficamente dispersas, reconstituem um cenário que marca certa distinção social, relativa à maneira pela qual, demograficamente, seus usuários estão dispostos on-line e off-line.

\section{Qualidade de vida e apoio social}

O aspecto geral da qualidade de vida, como é possível observar pelos resultados, foi relatado de maneira satisfatória em todos os domínios coletados. Entretanto, quando se analisam os domínios individualmente, constatamos percepçôes mais baixas para os itens "relações sociais" e "meio ambiente". Sobre o apoio social, há correlaçôes positivas e de magnitude moderada entre os domínios psicológico, relações sociais e meio ambiente, com a disponibilidade de informação, disponibilidade de interação social positiva e de apoio afetivo e emocional.

Diante do exposto, quais seriam as possíveis razóes da perspectiva sociológica para a diminuição dos indicadores de qualidade de vida por meio dos domínios "relaçôes sociais" e "meio ambiente"?

Em primeiro lugar, é importante considerarmos que a amostra foi composta por interlocutores que buscavam relações amorosas, sexuais e/ou de amizade on-line, cujas preferências e desejo eram mantidos frequentemente no anonimato, uma vez que metade da amostra relatou que vivia as relaçóes homossexuais em segredo ( $\mathrm{N}=51)$ (Tabela 1). Nota-se, ainda, que a amostra foi composta também por sujeitos que na maturidade deixaram de manter relaçôes heterossexuais para se relacionar com o mesmo sexo, rompendo com os laços familiares preestabelecidos via casamento e perdendo, em grande medida, parte considerável dos vínculos com as redes de apoio e suporte social formadas durante a vida - isto é, com a família biológica.

Estes pontos, portanto, nos permitem refletir sobre as possíveis consequências negativas em torno das percepçôes de qualidade de vida e de apoio/suporte social encontradas. A trajetória pessoal interpretada pelos dados sociodemográficos relativos aos tópicos "situação conjugal" e "homossexualidade" é reveladora de uma amostra diversa, que concentra interlocutores casados, separados/divorciados, solteiros ou viúvos, o que pode ser explicado também pela natureza do estudo por conveniência.

Apesar das limitaçôes em termos de seleção e formação amostral, principalmente pela já relatada dificuldade de recrutamento e adesão à pesquisa, a diversidade de 
sujeitos reitera ao menos dois aspectos relevantes do ponto de vista das redes e do acesso a espaços de sociabilidade on-line:

1) a possibilidade de buscar parceiros e de socializar com pessoas de diferentes lugares, sem o ônus da exposição e revelação pública, especialmente para aqueles sujeitos que buscavam relaçôes de modo anônimo, até mesmo sobre os que inferiram estar casados ( $\mathrm{N}=28)$ (Tabela 1);

2) o impacto positivo sobre a qualidade de vida a partir da formação de espaços mediados digitalmente, os quais propiciam a formaçáo de redes de apoio e suporte social, sobretudo para pessoas que romperam os laços anteriores com a família de origem, após a revelação das preferências amorosas e sexuais.

$\mathrm{O}$ impacto positivo em relaçáo à qualidade de vida e ao apoio/suporte social também pode ser analisado sob o prisma da religiáo. Conforme demonstrado na Tabela 1, houve uma incidência considerável de pessoas que descreveram ter uma crença religiosa e frequentarem algum templo, com destaque para aqueles interlocutores que relataram serem adeptos do protestantismo, espiritismo ou catolicismo, cuja soma evidencia mais da metade da amostra. As religiōes, de modo geral, alcançam diversos âmbitos da vida, desde as relações interpessoais, passando pelos aspectos socioculturais e intrapsíquicos. Segundo Henning-Geronasso e Moré (2015) e Scorsolini-Comin e Ribeiro (2017), as religiōes podem influenciar as percepçóes subjetivas e coletivas sobre grupos, práticas e sujeitos, oferecendo princípios e valores para a organização da vida social, que invariavelmente produzem significados acerca das práticas sociais, da sexualidade e do comportamento sexual.

De acordo com Duarte (2005), nas últimas décadas ocorreram diversas mudanças no campo religioso, especialmente pela crescente de religióes evangélicas pentecostais e dos movimentos espiritualistas e carismáticos. Tal fenômeno, também evidenciado pelos dados no que toca à incidência do protestantismo e espiritismo, integra um momento histórico em que não há apenas a prevalência do catolicismo frente às outras religiôes. A escolha por templos espíritas, protestantes, inclusive católicos, neste caso, pode estar relacionada a uma maior abertura dessas religióes nas últimas décadas, bem como em relação a uma maior aceitação das homossexualidades nos chamados "elementos microssistêmicos" da religiáo - os quais, de acordo com ScorsoliniComin e Ribeiro (2017), se configuram nas pequenas comunidades locais a partir das relaçóes estabelecidas entre elas e nas formas de acolhimento de seus membros; o 
que pode diferir - em partes - do ordenamento religioso clássico, reproduzido pelos livros e escrituras oficiais - os chamados "elementos macrossistêmicos".

\section{As descriçóes nos perfis e as buscas}

Durante a coleta de dados, percebemos também que as descriçôes mais prevalentes utilizadas pelos usuários buscavam se desvencilhar de noções que pudessem remeter ao universo da maturidade e velhice depreciadas. Assim, emergiram termos como "coroa", "homem", "urso", "paizão", "sarado", "maduro", "discreto", "fora do meio" etc (Figura 1). Isso, pois o mercado erótico que vigora nas redes on-line de busca de parceiros é altamente corporalizado e segmentado, quer seja pela linguagem escrita o que inclui a descrição pessoal e física nos perfis, apelidos e preferências - quer seja pela linguagem imagética, a partir do compartilhamento de fotos e vídeos pessoais (CASTELLS, 2011; MISKOLCI, 2015; 2017).

As categorias, além disso, tramam um etos específico a este grupo, em termos geracionais, pois são sujeitos que tencionam representaçôes modelares do desejo advindas da experiência com as mídias de massa e, contemporaneamente, também com as mídias digitais. Autores como Hostetler (2004), Weeks (1983), Kimmel (1977) e Gagnon e Simon (1973) explicam que tanto na literatura quanto no imaginário social dessa geração, que nasceu entre 1960 e 1978, as imagens de velhice foram especialmente vistas sob a ótica heterossexual, o que nos dá pistas para argumentar sobre o nascimento das categorias "coroa" e "paizáo", por exemplo, em contexto nacional. Segundo Simóes (2011) e Henning (2016), esses termos buscam valorizar o sex appeal da idade, removendo a carga negativa proveniente de apelidos estigmatizados e que poderiam constranger sujeitos mais velhos, além de salvaguardar representaçóes socialmente avaliadas como "bem-sucedidas", cujos modelos disponíveis ainda são, não por acaso, oriundos de uma matriz heterossexual (MISKOLCI, 2015; BUTLER, 2003; FRY, 1982).

A despeito disso, devido à hipersexualização das relaçóes entre homens, o regime representacional da homossexualidade seguiu um caminho diverso às representaçôes heterossexuais em termos de imagens (ILLOUZ, 2012). No contexto brasileiro há ainda a tentativa de compensação de estigma, quer seja pela emergência de categorias que reiteram um não-lugar à homossexualidade masculina, tais como "discreto" e “homem" (MISKOLCI, 2017; FERREIRA, 2017; BUTLER, 2003; FRY, 1982), quer 
seja pela insígnia do pânico sobre corpos feminilizados, fragilizados e até mesmo patológicos, os quais são projetados de maneira positivada nos descritores "sarado", "atlético" e "paizão", por exemplo. A representação criada por tais descritores atua, em termos psíquicos e culturais, como uma fantasia partilhada pelos sujeitos, a qual é concebida a partir de uma realidade hostil e hegemonicamente orientada para a heterossexualidade (MISKOLCI, 2017). Além disso:

Se o desejo pode ser compreendido como busca de reconhecimento de si por meio do desejo do outro, é na busca pelo reconhecimento pelo homem heterossexual másculo que atualmente funcionam essas plataformas. Ainda que ele não esteja presente ali - ou talvez nem mesmo exista -, por meio de um deslocamento imaginário ele passa a ser corporificado nos sujeitos "masculinos" e que se "passam por hétero" nas plataformas, os quais têm transferido para si - mesmo que de forma efêmera e contestável no mundo off-line - o poder de separar os eleitos para o amor e o prazer dos relegados à abjeçáo e ao desprezo (MISKOLCI, 2017, p. 258).

Segundo Guimarães (2004), Perlongher (1987) e Ferreira (2017), o uso da categoria "discreto" entre sujeitos homossexuais foi historicamente demandado desde fins da ditadura militar nas grandes cidades brasileiras como São Paulo e Rio de Janeiro, embora haja registros dos usos já nos anos 1930 no Brasil. O termo "discreto" aglutina uma espécie de demanda social por viver as experiências a morosas e/ou sexuais em segredo, uma vez que para muitas pessoas, ainda no presente, assumir o desejo pelo mesmo sexo publicamente requer um rompimento com a família, o enfraquecimento da rede primária de suporte/apoio social, a instabilidade no mercado de trabalho, alteraçóes nas percepçóes de bem-estar e na qualidade de vida, além da possibilidade de desencadear traumas e danos psicológicos.

Nesse caminho, Henning (2016) considera que as formas pelas quais sujeitos homossexuais têm se relacionado, no curso da vida, possibilitam compreender os percursos biográficos e as agências. Estes percursos, que integram os períodos da juventude, vida adulta, maturidade e velhice, revelam os paradoxos e dilemas para viver o desejo, estabelecer laços e redes, inclusive sobre os vínculos familiares e de amizade. Isso faz pensar, contudo, que as trajetórias contemplam realidades heterogêneas, como é possível concluir pelos dados reproduzidos, em que 27,2\% dos sujeitos entrevistados relataram ser casados, enquanto 9,7 estavam separados/ divorciados. Da amostra, 49,5\% de interlocutores, isto é, praticamente a metade, afirmou viver a homossexualidade de maneira não assumida para família, entre 
colegas de trabalho, amigos etc., recorrendo a sites de relacionamento em segredo, a fim de socializar e buscar parceiros.

Por último, há também aqueles que se descreviam como sujeitos "fora do meio", os quais segundo Miskolci (2017) - em análise sobre o termo entre jovens homossexuais na cidade de São Paulo -, remetem a uma busca insuspeita que não associe as práticas sexuais e amorosas a corporalidades e representaçóes patologizadas. Essas representaçóes, de acordo com o autor, se materializaram em meio ao auge das mortes provocadas pela epidemia de HIV-Aids - grosso modo a partir de 1985 até a invenção e disseminação do coquetel antirretroviral em fins dos anos 1990 - e passou a descrever sujeitos que não estavam vinculados ao "meio gay" e, portanto, fora de risco de contaminação (FERREIRA; MISKOLCI, 2020; PELÚCIO; MISKOLCI, 2009; GILMAN, 1991; POLLAK, 1990). Os usos do termo "fora do meio", em associação com o "discreto", "sarado" e "atlético", evocam ainda noçôes de corporalidade oriundas de modelos de masculinidade hegemônica vigentes socialmente, como também a recusa de aspectos opostos, tais como afeminamento, fragilidade, sobrepeso ou magreza e indiscrição.

\section{Considerações finais}

Finalmente, os dados apresentam um balanço parcial e, ao mesmo tempo, significativo para o tipo de estudo e pela natureza da amostra, trazendo contribuiçóes sobre as dimensóes de qualidade de vida e apoio/suporte social, além de uma interface com pesquisas sociológicas realizadas na cidade de São Paulo, com recortes de idade e sexualidade semelhantes.

A descrição dos domínios da qualidade de vida e apoio/suporte social, a partir dos questionários WHOQOL-bref e da Escala de Apoio Social - MOS -, permite constatar aproximaçóes e correlaçóes entre estes, maiormente positivas e de magnitude moderada.

$\mathrm{O}$ estudo avança também ao tratar de aspectos relativos às descrições dos interlocutores contidas nos perfis das plataformas on-line utilizadas e sobre as características sociodemográficas, por meio de uma amostra formada por sujeitos de meia-idade e que na maturidade passaram a se relacionar com o mesmo sexo. É possível concluir, preliminarmente, que as buscas e a maneira de se autodescrever reiteram padrōes modelares de gênero e sexualidade, cujo significado consiste em 
negar visibilidade às relaçôes sexuais e amorosas entre o mesmo sexo, reproduzindo expectativas heteronormativas de desejo, as quais historicamente concebem as relações homossexuais como imorais, reprováveis, desviantes e até mesmo patológicas. Por outro lado, elas também funcionam como categorias estratégicas, as quais são demandadas frequentemente por sujeitos que ainda vivem a experiência homoerótica em segredo, e mantêm laços próximos e fortes com a família, sobretudo em relação aos casados e àqueles que não se assumiram publicamente.

A criação de laços fracos nas mídias pode ser sintomática do desejo de manter relaçôes efêmeras e não duradouras on-line, de modo que elas não enfraqueçam os laços fortes preestabelecidos no ambiente da família, do trabalho e do lazer, o que invariavelmente também pode culminar em vulnerabilidade emocional e afetiva, tendo em vista que as relações amorosas serão concebidas por laços potencialmente fracos e provisórios. A contradição entre, por um lado, estabelecer laços fortes nas redes familiares e, por outro, constituir laços fracos nas relaçóes homossexuais nas mídias digitais é, por fim, um indicador simbólico que aponta para o reconhecimento social negativo da esfera sexual.

Não obstante, apontamos para a necessidade de se utilizar outras técnicas e métodos de pesquisa, a fim de explorar de modo mais robusto os dados para amostras desta natureza; a saber: entrevistas semiestruturadas, tópicos guia, análise da rede familiar e social por meio de genograma e ecomapa, netnografia, snowball, dentre outras. $\mathrm{O}$ enfoque qualitativo em pesquisas futuras é indispensável para tecer aproximaçóes e distanciamentos entre as características sociodemográficas, descritivas e relativas à qualidade de vida, bem como em relação ao percurso pessoal dos interlocutores. É preciso, por fim, evitar generalizaçôes a respeito dos dados, tendo em vista que a natureza amostral se deu por conveniência e, portanto, não é possível dizer que os dados obtidos para este perfil contemplam, concretamente, os aspectos sociodemográficos, de qualidade de vida e de apoio/suporte familiar e social, para todos os sujeitos homossexuais idosos e de meia-idade que atualmente utilizam plataformas on-line para buscar parceiros. ${ }^{1}$

\section{Agradecimentos}

À Fundação de Amparo à Pesquisa do Estado de São Paulo (FAPESP) (Processos 13/22923-3 e 15/05623-1), pelo financiamento e suporte à presente pesquisa. 


\section{Referências}

ASSOCIAÇÃO BRASILEIRA DE EMPRESAS DE PESQUISA (ABEP). Critério de classificação Econômica Brasil. Brasília: CCEB, 2012.

BAYM, N. Personal connections in the digital age. Cambridge: Polity Press, 2010.

BELELI, I. Amores on-line. In: PELÚCIO, L.; SOUZA, L.A.F.; SABATINE, T.T., (Coord.). Olhares plurais para o cotidiano: gênero, sexualidade e midia. Marília: Cultura Acadêmica, 2012, p. 56-73.

BRAH, A. Diferença, diversidade e diferenciação. Cadernos Pagu, v. 26, p. 329-376, 2006.

BRASIL. Portaria n. 2.528, de 19 de outubro de 2006. Aprova a Política Nacional de Saúde da Pessoa Idosa. Brasília: Diário Oficial da República Federativa do Brasil. Brasília, 2006.

BUTLER, J. Problemas de gênero: feminismo e subversão da identidade. Rio de Janeiro: Civilização Brasileira, 2003.

CASTELLS, M. A sociedade em rede. São Paulo: Paz e Terra, 2011.

DIJCK, J.V. The culture of connectivity: a critical history of social media. Oxford: Oxford University Press, 2013.

DUARTE, L. F. D. Ethos privado e justificação religiosa: negociaçôes da reprodução na sociedade brasileira. In: HEILBORN, M.L.; DUARTE, L.F.D.; PEIXOTO, C.; BARROS, M.L., (Coord.). Sexualidade, família e ethos religioso. Rio de Janeiro: Garamond, 2005, p. 137-176.

FACIOLI, L.; MISKOLCI, R. Conectadas: experiência de subalternidade e ajuda mútua feminina on-line entre mulheres de classes populares. Revista Mediaçôes, v. 20, n. 2, p. 129-159, 2015.

FERREIRA, J. P. Desejos comodificados: dos classificados aos perfis na busca por parceiros do mesmo sexo. 2017. Dissertação (Mestrado em Sociologia) - Centro de Educação e Ciências Humanas, Universidade Federal de São Carlos, 2017.

FERREIRA, J. P.; MISKOLCI, R. O desejo homossexual após a AIDS: uma análise sobre os critérios acionados por homens na busca por parceiros do mesmo sexo. Ciência \& Saúde Coletiva, v. 25, n. 3, p. 999-1010, 2020.

FRY, P. Da hierarquia à igualdade. In: FRY, P., (Coord.). Para inglês ver: identidade e politica na cultura brasileira. Rio de Janeiro: Zahar, 1982. p. 87-115.

GAGNON, J.; SIMON, W. Sexual deviance. New York: Harper and Row, 1973.

GILMAN, S. L. Disease and representation: images of illness from madness to AIDS. New York: Cornell University Press, 1991.

GOLTZ, D. Queer temporalities in gay male representation: tragedy, normativity, and futurity. New York: Routledge, 2010. 
GRIEP, R. H.; CHOR, D.; FAERSTEIN, E.; WERNECK, G.; LOPES, C. Validade de constructo de escala de apoio social do Medical Outcomes Study adaptada para o português no Estudo Pró-Saúde. Cadernos de Saúde Pública, v. 21, n. 3, p. 703-714, 2005.

GUEDES, M. B. O. G.; LIMA, K. C.; CALDAS, C. P.; VERAS, R. P. Apoio social e o cuidado integral à saúde do idoso. Physis Revista Saúde Coletiva. Rio de Janeiro, v. 27, n. 4, p. 1185-1204, 2017.

GUIMARÃES, C. D. O homossexual visto por entendidos. Rio de Janeiro: Garamond, 2004.

HENNING, C. E. "Na minha época não tinha escapatória": teleologias, temporalidades e heteronormatividade. Cadernos Pagu, v. 46, p. 341-371, 2016.

HENNING-GERONASSO, M. C.; MORÉ, C. L. O. O. Influência da religiosidade/ espiritualidade no contexto psicoterapêutico. Psicologia: Ciência e Profissão, v. 35, n. 3, p. 711-725, 2015.

HOSTETLER, A. Old, gay, and alone? The ecology of well-being among middle-aged and older single gay men. In: HERDT, G.; DE VRIES, B., (Coord.). Gay and lesbian aging: research and future directions. New York: Springer, 2004. p. 143-176.

LLOUZ, E. Why love hurts? a sociological explanation. London: Polity Press, 2012.

INOUYE, K.; BARHAM, E. J.; PEDRAZZANI, E. S.; PAVARINI, S. C. I. Percepçóes de suporte familiar e qualidade de vida entre idosos segundo a vulnerabilidade social. Psicologia: Reflexão e Crítica, v. 23, n. 3, p. 582-592, 2010.

INSTITUTO BRASILEIRO DE GEOGRAFIA E ESTATÍSTICA. Sintese de indicadores sociais: uma análise das condiçôes de vida da populaçâo brasileira. Brasília: IBGE, 2016.

KIMMEL, D. C. The aging male homosexual: myth and reality. The Gerontologist, v. 17, n. 4, p. 328-332, 1977.

MARTINO, L. M. S. Teoria das midias digitais: linguagens, ambientes e redes. Petrópolis: Vozes, 2015.

MELCHIORRE, M. G. et al. Social support, socio-economic status, health and abuse among older people. Seven European Countries, v. 8, n. 1, p. 548-556, 2013.

MISKOLCI, R. "Discreet and out of the gay scene" - notes on contemporary sexual visibility. Cadernos Pagu, v. 44, p. 61-90, 2015.

MISKOLCI, R. Desejos digitais: uma análise sociológica da busca por parceiros on-line. Belo Horizonte: Autêntica, 2017.

MISKOLCI, R. Networks of desire: the specter of AIDS and the use of digital media in the quest for secret same-sex relations in São Paulo. Vibrant, v. 10, n. 1, p. 40-70, 2013. 
MOTTA, M.P. Ao sair do armário, entrei na velhice: homossexualidade masculina e curso da vida. Rio de Janeiro: Mobile, 2014.

NERI, A. L.; VIEIRA, L. A. M. Envolvimento social e suporte social percebido na velhice. Rev. Bras. Geriatr. Gerontol. Rio de Janeiro, v. 16, n. 3, p. 419-432, 2013.

NICOLACI-DA-COSTA, A.A. Revoluções tecnológicas e transformações subjetivas. Psicologia: Teoria e Pesquisa, v. 8, n. 2, p. 193-202, 2002.

PELÚCIO, L.; MISKOLCI, R. A prevenção do desvio: o dispositivo da AIDS e a repatologização das sexualidades dissidentes. Sexualidad, Saludy Sociedad, v. 1, p. 125-157, 2009.

PERLONGHER, N. O negócio do michê: prostituição viril em São Paulo. São Paulo: Brasiliense, 1987.

POCAHY, F.A. Entre vapores \& vídeos pornôs: dissidências homo/eróticas na trama discursiva do envelhecimento masculino. Revista Estudos Feministas, v. 20, n. 2, p. 357-376, 2012.

POLLAK, M. Os homossexuais e a AIDS: sociologia de uma epidemia. Estação Liberdade: São Paulo, 1990.

SAGGESE, G.S.R. Entre perdas e ganhos: homossexualidade masculina, geração e transformação social na cidade de Sáo Paulo, 2015. Tese (Doutorado em Antropologia). Instituto de Filosofia e Ciências Humanas. Universidade de São Paulo, 2015.

SANTOS, E. N.; PEREIRA, P. P. G. Amores e vapores: sauna, raça e prostituição viril em São Paulo. Revista Estudos Feministas, v. 24, n. 1, p. 133-154, 2016.

SCORSOLINI-COMIN, F.; RIBEIRO, L. M. Relaçôes entre religiosidade e homossexualidade em jovens adultos religiosos. Psicologia \& Sociedade, v. 29, n. 16, p. 1-11, 2017.

SIMÓES, J. A. Corpo e sexualidade nas experiências de envelhecimento de homens gays em São Paulo. A Terceira Idade, v. 22, n. 51, p. 7-19, 2011.

WEEKS, J. Os problemas dos homossexuais mais velhos. In. HART, J.; RICHARDSON, D. (Coord.). Teoria e prática da homossexualidade. Rio de Janeiro: Zahar, 1983.

WELLMAN, B. Physical place and cyberplace: the rise of networked individualism. International Journal of Urban Research, v. 25, n. 2, p. 227-252, 2001.

WHOQOL GROUP. The World Health Organization quality of life assessment (WHOQOL): position paper from the World Health Organization. Social Science \& Medicine, v. 41, n. 10, p. 1403-1409, 1995.

ZAGO, L. F. Os meninos - corpo, gênero e sexualidade através de um site de relacionamentos, 2013. Tese (Doutorado em Ciências Sociais). Instituto de Filosofia e Ciências Humanas. Universidade Federal do Rio Grande do Sul, 2013. 


\section{Nota}

${ }^{1}$ João Paulo Ferreira foi responsável pela concepção, coleta e análise dos dados, busca de financiamento, pesquisa e metodologia. K. Inouye responsabilizou-se pela concepção, coleta e análise dos dados, busca de financiamento, pesquisa, metodologia e administração do projeto de pesquisa. R. Miskolci realizou a concepção, pesquisa, metodologia e administração do projeto de pesquisa. 


\section{Abstract}

Middle-aged and old-aged homosexual men in digital media: self-description, social support and quality of life

This study aims to identify and analyze the indicators of quality of life and social support, as well as the profile descriptors used by middle-aged men who seek and/ or are interested in same-sex relationships on digital platforms. The methodological design was quantitative, descriptive and cross-sectional. The data have been collected through a socio-demographic questionnaire, the WHOQOL-bref and the Medical Outcomes Study (MOS) Social Support Scale, and analyzed using the Statistical Package for the Social Sciences ${ }^{\circledR}$ (SPSS). The results confirmed that the most prevalent descriptors were those that sought to get rid of notions that could associate maturity and old age with disability and frailty, in addition to strengthening positive and sexualized hegemonic representations of masculinity. In relation to the total scores of social support and quality of life, these showed a directly proportional, significant and moderate correlation $(\mathrm{rho}=0.609, \mathrm{p}<0.001)$.

Keywords: homosexuality; aging; quality of life; social support; digital media. 